\title{
From Artifacts to Experiences: Brands in the Era of Prosumeration
}

\author{
Dimitar Trendafilov
}

\begin{abstract}
Consumer behavior is a complex and dynamic phenomenon as it embraces cultural and social aspects, previous experience and mass media influence. This paper proposes that in order to study how brands frame consumers' perception and preferences an interdisciplinary perspective is fruitful. It uses a socio-semiotic perspective to define and analyze some contemporary marketing practices in brand building and consumer relationship management that demonstrate the relativity of the notion of "product" and underline the active communicative interaction between a brand and its consumers regarding the experience provided. Some of the most prominent analytical models of the product value building are presented, along with a discussion of the cultural typology of experience production. Finally, it is argued that multimodality has a special place as an actual and useful tool for improving the communication management via sensorial and cognitive stimulation.
\end{abstract}

Keywords: brand, experience economy, multimodality, product construction

\section{Introduction}

This article addresses three major trends. First, brands have been given back to the people, to whom they primarily belong because the power of brands is rooted not in factories and workshops but in the consumer's mind and behavior (Fournier, 1998; Bullmore, 2001; Kotler et al., 2010). Second, even with some limitations, semiotics has confidently taken on an important role in branding, market research and management (Floch, 2001; Marrone, 2007; Batey, 2008; Lindemann, 2010; Oswald, 2012, 2015). Third, experience has become the new mantra in marketing discourse as a whole, as we show with many examples below.

In an economy based on and dominated by consumers' perceptions and values (Codeluppi, 2001; Piercy, 2009; Keller et al., 2012), the product is becoming an increasingly vague notion; therefore, it is getting harder and harder for companies to produce adequate products. Products' physical attributes and direct benefits are an object of evaluation of the contemporary consumer that goes beyond the facilities and engineering standards that the companies put into the production process. Thus, producers understand what the real value they provide is to the consumers after product launching but not before that. Consumer value differs from the notion "added value chain" that businesses usually employ to describe how a given product concentrates value during its path from raw materials to the shelf and is crucial as a competitive advantage.

This situation opens up considerable opportunities for a socio-cultural semiotics to contribute to the analysis of brand meaning and for participating in strategic communication projects (Copley, 2004). As Prahalad and Krishnan (2008) put it, in the digital, network-based age the transformation towards consumer-centricity and strategic partnership affects all businesses and is not a matter of choice. They highlight some key elements of the transformation at stake, while pointing out that "value is shifting from products to solutions and experiences" and "no company has all the resources it needs to create unique personalized experience" (Prahalad and Krishnan 2008, p. 24 ff.). This difficulty forces managers to be more open towards collaboration and more sensitive to trends and changing environmental conditions, including searching for new value sources outside the product and among various 
stakeholders, involving smaller groups (communities, clubs or just a circle of enthusiasts) and even individual consumers (Pine et al., 2000). The contribution of brand semiotics as a subfield of semiotics (Marrone, 2007, Batey, 2008, Oswald, 2012) in this marketing environment can be highly helpful in analyzing, foreseeing and proposing product development, communication and design trends. The limitations of the article allow for only a few aspects to be outlined regarding the semiotic nature of brands and their experiential marketing performance, and the socio-semiotic tactics that managers have at their disposal to communicate the brand message via methods introduced by multimodality - a semiotic area that studies the multi-channel performance in the interaction (Section 4).

Consumer experience is a set of various services (such as delivery, entertainment, enjoyment, being somewhere, sensory stimulation, et cetera) that go beyond the products themselves. Those services can be designed, run and modified according to the need of small scale market groups or even for a single consumer (Oswald, 2015). At this new center of branding activities are the consumers. They are simultaneously senders and receivers, as well as users, creating personal value(s) (meaning) with these brand(s), all of which makes the consumer an actual participant in product development (Joseph, 2010). The co-operation between consumer and producer in market exchanges is almost obligatory and their relationship is a two-way street, as we will see throughout this text. The notion of "prosumer", suggested by Marshall McLuhan (1972), Alvin Toffler (1980, p. 266) and Philip Kotler (1986) long time ago, has actually come to life. Those authors considered technologies as a motive power for closing the gap between producing and consuming side of the market which would change the market forever as mixing their traditional roles.

Keller (2013) states that establishing brand awareness first and foremost requires repeated exposure: "the more a consumer 'experiences' the brand by seeing it, hearing it, or thinking about it, the more likely he or she is to strongly register the brand in memory" ( 2013 , p. 75). It is reasonable to consider experience as the most influential factor in the decisionmaking process, even more influential than price, quality and reputation/recommendation (Keller, 1998, p. 103; Keller et al., 2012, p. 63). It is more likely to be aware of a good car by using it, and not simply by looking at, even though the car may possess an attractive design and a long list of useful features.

In their research, Brakus et al. (2009) support the argument that brand experience differs from commonly shared assumptions in brand management. Their research results suggest that "the brand experience scales display discriminant validity from some of the most widely used branding measures and scales, including brand evaluation, brand involvement, brand attachment, consumer delight, and brand personality" (Brakus et al., 2009, p. 65). It comes to show the importance of experience as a particular brand feature that directly affects consumer satisfaction and loyalty. In addition, as the authors conceptualize it, experience is based on responses to sensations, feelings, behavior and cognitions proceeding from particular brand-related stimuli that should be considered as different but not derivative evaluative and associative construct such as brand attitudes, attachment or personality (Brakus et al., 2009, p. 53). Demand of experience puts a significant challenge before managers to plan and design some experiential performance of their products from the outset as an immanent part of the product consistent with the brand's essence. A product could deliver experience in its immediate use situation as well as in wider context that allows more services and stimulations to occur. Sometimes management can control the context (retail environment, product's technical performance) but more often they do not. This is what Bullmore (2001) highlights by specifying that consumers meet brands in so many places and situations that companies are capable of influencing only the transmission of some brand stimuli, e.g. as advertising, packaging or price, whilst the reception and interpretation always remains consumers' 
activity. In this context, semiotics becomes increasingly important in scrutinizing the sources of brand experience and in providing a toolkit for managing the points where behavior of given brand meets and provokes behavior of the consumer.

Just like conventional advertising, brand reliance and imagery, brand experience aims meaning creation but by employing different channels of interactions with consumers that allow sensory and cognitive stimulations of various kinds. From this point of view, semiotics has to do with emotions, community sensation, and intentionally building brand reality, or, in other words, consumer immersion in multidimensional branded environment (Oswald, 2015, p. 90; Lindemann, 2010, p. 158).

This article aims to put the general theory of product semiotization (as opposed to commoditization) in the broader picture of experience-economy we witness (Appadurai, 1986, Mick et al., 2004, Marrone, 2007, Batey, 2008, Holt and Cameron, 2010). With regard to this semiotization process some recent examples are presented also in order to illustrate how big brands (as Google, Apple and some big coffee producers) control their experiential aspects according to the characteristics of their products and the interests of the consumers. Multimodality is discussed separately as an actual tool for analyzing and improving a brand's communication system, which usually is highly complex and uses many channels. Semiotics has already contributed significantly to the theory of communication by explaining it as signexchange serving various purposes at the basis of a culture (Barthes, 1972; Eco, 1976; Lotman, 1992; Williamson, 2000; Floch, 2001; Mick et al., 2004, Batey, 2008). Since experience could be considered as a communication process in branding, multimodality enables managers to deconstruct and reconfigure their brands' sensorial and intellectual approach towards the audience. It could happen in various ways - through combination of senses, collective practices and in-store storytelling.

\section{The experiential turn - or return}

First of all, we should point out that experience as a managerial leverage in branding is a relatively new topic. The concept of "experience" as a significant aspect of consumption first appeared in the article by two marketing specialists regularly using a semiotic approach. Holbrook and Hirschman (1982) make a short overview on the undervalued role of multisensory and aesthetic enjoyment, fun, daydreaming and fantasies, time budgeting in the pursuit of pleasure, and emotions (i.e. arising feelings from consumption) in consumer behavior while marketers usually consider it as a consecution of reasonable decisions (summarized in the term "information processing"). The authors remind that experiential perspective "regards consumption as a primary subjective state of consciousness with a variety of symbolic meaning, hedonic responses, and esthetic criteria" (Holbrook and Hirschman, 1982, p. 132). In this train of thought they outline a general model shown in Figure 1 below, which represents a simplified schema of the multifaceted interaction between environment (product, [non]verbal stimulus, and communication) and organism (resources, tasks, search activities, type of involvement [cognitive responses, orientation, arousal], and individual differences such as personality, demographics, religion, sensation seeking, lifestyle, etc.).

Obviously, product perception is a set of many elements that work together before and after the purchase. Some of the elements are very personal in nature, other - social-cultural biased, but most certainly both need special attention and research approach by the marketers. By their semiotic standpoint, Holbrook and Hirschman (1982, p. 137) insist that buying ${ }^{1}$ and

\footnotetext{
${ }^{1}$ Just like Kahneman confirms (2013), they consider "buying" as a culmination of antecedent decision-making process that is more interesting for traditional consumer research (Holbrook and Hirschman, 1982, p. 137) as far
} 
consumption are two different things and in the moment of consumption the product becomes meaningful because of the user and not necessarily because of its functional assets; moreover, it goes far beyond its everyday usefulness. Here the experiential aspects emerge from the consumption in the form of extracting fun, pleasure, enjoinment and even knowledge from given product, on the one hand, and adding more or less personal symbolic meaning, on the other hand.

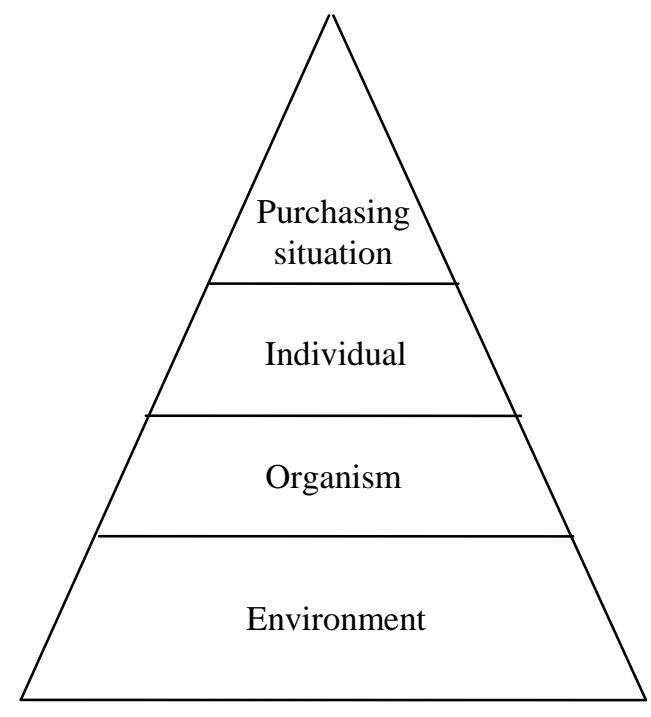

Figure 1. The model, based on Holbrook and Hirschman (1982), shows the levels (groups of factors - from general to more particular) that regular consumer is influenced by till the moment of product choice (D.T.).

Pine and Gilmore (1999) use "experience" as a technical term in order to describe stages of the so-called developed economies. Along with the product benefits, experience is a "qualitative" revolution in market demand, and is even more powerful in knitting together physical goods and the services related with them, in essence providing new, higher levels of valuation on behalf of the consumers. Regarding "experience", it means that consumers are considered as a center of both marketing efforts and business as a whole. Pine and Gilmore (1999) even claim that the consumer is the "new product". In a broader sense, the concept of "experience" denotes the consumer's satisfaction of knowledge and aesthetic needs. They discuss certain features serving as "modules" 2 in order to differentiate stages in economic evolution (see Table 1). Among them is consumer experience that should provide stimuli in which consumers should react to (sensually, intellectually, bodily, and socially) and "experience providers" embracing communications, identity (brand name, logo, symbols, characters), product design, availability, co-branding, situation (context) of consumption, websites, people (appearance and communication skills of the employees) (also Lindemann, 2010, p. 157).

\footnotetext{
as it considers information gathering and processing regarding the product, which is different from experience

${ }^{2}$ Baldwin and Clark (2000, p. 36), for example, identify "modularity" as a key invention (during late 1960's by IBM) which provided enormous flexibility. It became possible due to advanced technologies, that made breaking up a product into subsystems or modules. In terms of marketing, "modularity in use allows consumers to mix and match elements to come up with a final product that suits their tastes and needs [...] Modularity in use can spur innovation in design: the manufacturers can independently experiment with new products and concepts, such as futon mattresses or fabric blends, and find ready consumer acceptance as long as their modules fit the standard dimensions" (Baldwin and Clark, 2000, p. 39).
} 
Table 1. Pine and Gilmore's (1999, p. 5) distinctive characteristics of experience according to the evolution of economic units produced through the world's economic history

\begin{tabular}{|c|c||}
\hline $\begin{array}{c}\text { ECONOMIC } \\
\text { UNITS }\end{array}$ & DISTINCTIVE CHARACTERISTICS \\
\hline Commodities & Basic materials extracted from the natural world \\
\hline Goods & Tangible products that companies standardize and then inventory \\
\hline Services & Intangible activities performed for the particular consumer \\
\hline Experience & Memorable events that engage individuals in a personal way \\
\hline
\end{tabular}

In an experience economy, the attributes are personalized, the buyer is the guest, and the demand is sensation (Pine and Gilmore, 1999). In a sense, experience has something in common with the first stage of human economic evolution - the agrarian one - during which people were directly involved in the production process and in most cases, they were end consumers of those products too. They literally lived through and enjoyed their bread, clothes and houses they created by their own hands. However, the parallel stops here. We are concerned with the highest levels of needs satisfaction (desire) according to Maslow's hierarchy of needs, concerning knowledge, aesthetics and even self-actualization, not the basic ones (Oliver, 1999, p. 51).

The types and forms of experience that merit attention from a semiotic perspective are consumer lifestyles and identity shifting, consumer "journeys" in retail environment, theme parks and tourism products, augmented reality, brand communities (both off- and online), consumer sharing of brand/branded information. ${ }^{3}$ Consumers are able to express their opinion in brand related topics online (24/7), they participate in real time video games and special events, use packaging for personalization (e.g. Coca-Cola and Famous Grouse feature personal names on their bottle labels), etc. In a few words, the contemporary brand is a consequence of the promise of an experience that the company can deliver (Lindemann, 2010, p. 108).

\section{The semiotization of products}

From a semiotic point of view a non-branded product could not generate and maintain imagery and experience, except for immediate functional benefits. In such a case, what Levitt (1980) defines as a "generic" product suffers from the lack of a meaning axis that is able to produce centripetal force. Instead, brands need this axis because their respective names and logos should stand for something more: to convey a meaning beyond the mere product in order to generate future purchases, owing to a positive attitude. That is why there is a

\footnotetext{
${ }^{3}$ According to VALS segmentation system (Strategic Business Insight, 2015), there is a separate lifestyle group which is defined as "experiencers" (at least in the U.S. market, although the model is applicable anywhere). This segment is motivated by self-expression and is open to innovations and adventures. It consists of young and impulsive people who spend their income predominantly on fashion, entertainment and excitement activities and goods (in Kotler and Keller, 2012, p. 248). Obviously not all of the consumers perceive and value experience in one and the same manner. The members of the concerned group seek various and emotionally intensive products that may cater for variety, thrill and social expression.
} 
difference between a slogan and a general cultural message of a brand, on the one hand, and a tagline, on the other hand (Aaker and Joachimsthaler, 2000, p. 47). A non-branded product could be "new" and "good-working" while a branded product could be "exciting", "friendly", "inspiring", "superb", "sexy", etc. The list of options is almost endless. Brands shift the language by which consumers perceive and talk about products, they enrich that language by obtaining ideas, images and even fears from culture as a common reservoir of meanings as well as by actively participating in groups, events and activities directly related to brands.

Because culture provides various ways of avoiding the dependence and influence of immediate environment, the raw materials used in food supply and goods production are culturally determined. As a result, no goods are natural insofar as they fall under some classification imposed by religion, tradition, experience, or all together. This is true for the markets as exchange systems as well, and vary from culture to culture, limited or stimulated by power systems, religion, lack or abundance of natural resources, etc. (Kopytoff, 1986; Appadurai, 1986).

By putting together the two dimensions of culture (see Figure 2 below) in the brand management context - its function of separation and permeability control (or "framework"), on one hand, and its function of creating and recycling objects and meanings inside the system (conditionally called "production"), on the other hand, it is possible to ask where experience best works on the exemplary cultural map. As previously mentioned, the economy has developed significantly, but in a sense, it has looked back to its roots transforming the experience of production that was disregarded because of industrialization. The quadrants in a socio-cultural perspective, following the culture-as-framework axis, are individual and group. This is the most prominent dualism (dimension) in culture, which is widely used in sociology, cultural studies and political economy (see Trompenaars and Hampden-Turner, 1997 and Hofstede et al., 2010). It represents the endless dynamism of the relationships between the individual and his/her surrounding society. Because the major part of the products are made for the sake of satisfaction of the individual consumer needs, they always seem functional first and have been advertised as such, but after all most of the products have something to do with opinion and estimation by various groups of people surrounding the individual such as family, friends, colleagues, clubs, neighbors, etc. 


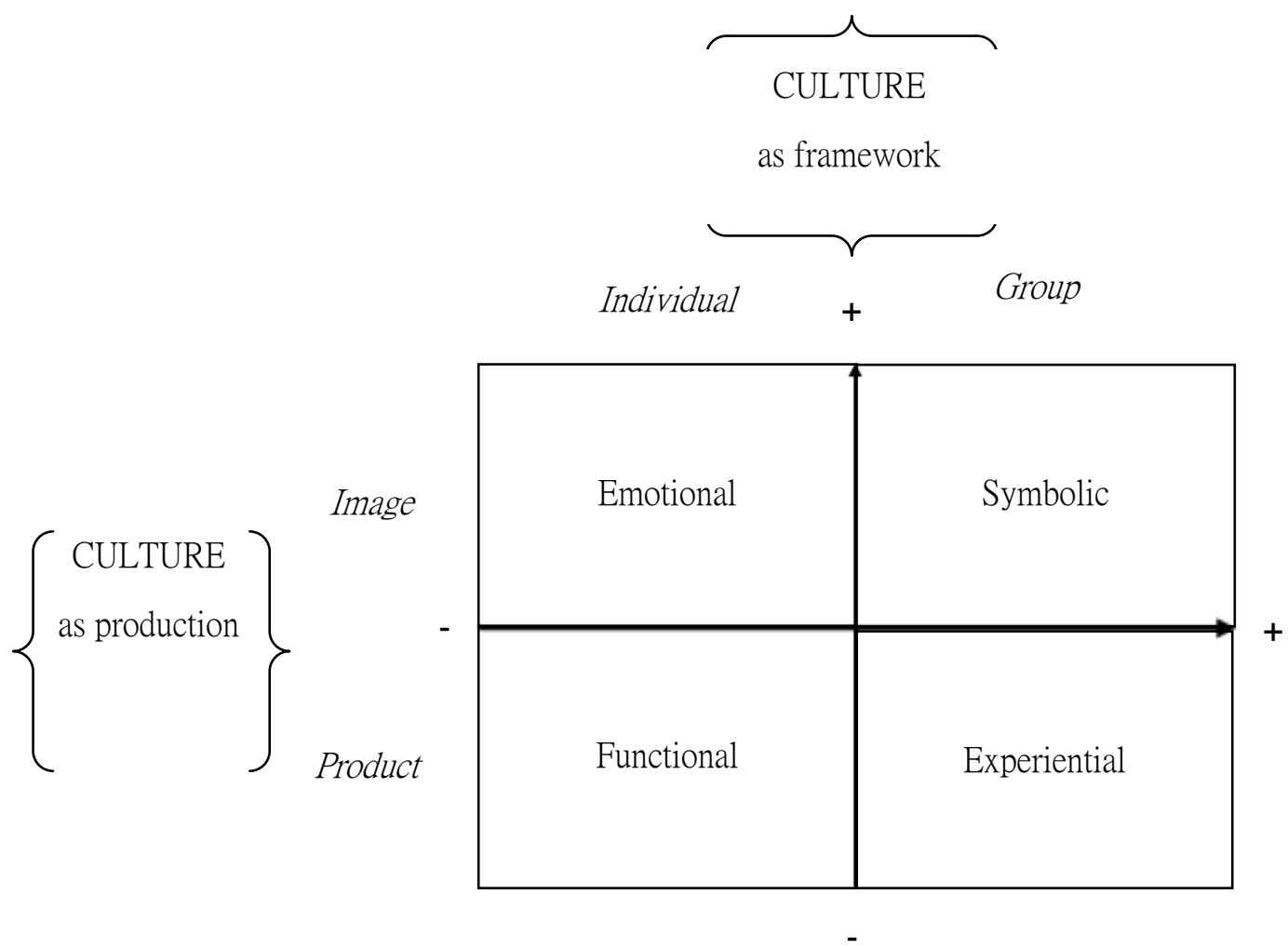

Figure 2. Types of consumption, driven by different dimensions of culture - personal and group behavior in terms of consumption (Solomon et al., 2006) and levels of production in terms of marketing and branding [Keller, 1998]. Author: D.T.).

The rich literature based in the qualitative research approach towards marketing phenomena demonstrates that the social element in consumption reinforces the experience effect and goes beyond mere "sensory" aspects of the product and the environment it performs in (Fournier et al., 2005; Schouten and McAlexander, 2005; Holt and Cameron, 2010). Pine and Gilmore explicitly notice this as well by pointing out the "social" factor $(1999$, p. 29, p. 46). It overgrows the basic performance of the products, but could not exist without it. Thus, the owners of Lacoste apparel, for instance, are prone to think of themselves as members of chic sports club, even though they do not actually practice any sport (Kapferer, 2012, p. 162). Insofar as it settles the spheres of action of these two aspects, as well as their controversial relations, culture determines the increase of the meaning of product from functional to experiential, on one hand, and from imagery to symbolic, on the other (the horizontal axis in Figure 2). Symbolic function is highly important for powerful brands but it derives from and depends on the social sphere of culture, e.g. reference groups and sub-cultures (Solomon et al, 2006, pp. 349 ff.).

The second axis in Figure 2, culture-as-production, includes product as functional tool and loaded with imagery as well as with any positive and unique associations a given brand needs (Keller, 2013; Piercy, 2009). The power of brands is in the rich, strong and distinctive associations they build and maintain, and they go beyond the pure economic and consumption sphere by connecting brands with societal issues (Klein, 2000; Rifkin, 2000; Codeluppi, 2001). Brand image on a personal level always has emotional nuance (Solomon et al., 2006). If a person is indifferent to the brand, it is a negative sign, at least of low involvement in the given category as a whole. Nevertheless, it still does not mean that consumers cannot "experience" a given product in various ways (Brakus et al., 2009, p. 53). This is the space 
where consumers make use of the functional benefits of the product in the first place, but the richer the brand's imagery the bigger the consumer's emotional consumption (vertical axis from minus to plus in Figure 2).

Consequently, it would be very difficult for experience to be pin-pointed to an exact place in the "cultural map", as that would misrepresent the multi-faced nature of experience in brand practice (see Oliver, 1999; Brakus et al., 2009, pp. 52 ff.). However, the argument here is that the strongest presence and value of experience exists in the space where "product" meets "group". In this way, the more people are involved, the stronger the brand's experiential centripetal force and brand associations will be. The availability of "people like us", "doing things we like" or "understanding the things around like us" creates and exaggerates brand experience. It does not matter if they are part-time-job coffee aficionados as in Starbucks' strategic approach (Holt and Cameron, 2010, p. 107), or average consumers who are members of a real community as in the case of Harley-Davidson Owners Group (Vincent, 2002, pp. 89-90; Schouten and McAlexander, 2005; Thompson and Arsel, 2004). Their passion and enthusiasm leave a powerful, emotional mark and make consumers literally feel the brand. In an earlier economic stage, selling a motorcycle ended the deal. In current consumption practices, however, it is only the beginning of the brand-consumer relations. What matters is the access to the brand culture, partnership and community (Rifkin, 2000; Fournier, 1998) or as Fournier (2009, p. 107) has generalized: "People are more interested in the social links that come from brand affiliations than in the brands themselves".

If we search for an example of how the brand experience model works in culture, we could refer to the critical analysis regarding the place of brands in contemporary complicated semiotic landscape made by Naomi Klein (2000, p. 49):

The effect, if not always the original intent, of advanced branding is to nudge the hosting culture into the background and make the brand the star. It is not to sponsor culture but to be the culture. And why shouldn't it be? If brands are not products but ideas, attitudes, values and experiences, why can't they be culture too?

This short quotation is a loud declaration (from the few announced outside the offices of marketing departments and advertising agencies) that there has been no other way for brands to reach such a significant level of influence on consumer and thence social behavior, unless brands possess the same rights as other parts and forms of culture. Brands do not exist in some parallel world since a culture is actually a closed system that accepts non-texts (i.e. texts that are not if its own production) from outside with difficulty and by means of serious translation (Lotman, 1992). On the contrary, brands obtain their power from cultural meanings, accumulate semiotic capital establishing relations with other cultural texts (Batey, 2008; Holt and Cameron, 2010; Thompson and Arsel, 2004, p. 639) and in the course of time, as Lotman would say, their messages gain a critical mass to the moment when they start spreading themselves like avalanches (1992, p. 25). Under the currently dominant semiotic systems of media and imagery, brands do not tend to be cultural products but cultural products act like brands. In this context, there is no difference between the experience provided by movies and carnivals, for instance, and that provided by branded events and spaces.

This principle of prosumeration has been followed closely by Google (2014) in their launching process which formulates the "best product" with the help of the consumers. The company's CEO points out (Google Inc., 2014) that in the very beginning they adopted in their innovation culture the practice of "beta launch" that allows them to revise and improve their products not before but after the point of launch for real use in the consumers' hands. Users indicate by themselves what they need more of, what they actually ignore, what they perceive as redundant, etc. While listening carefully to the feedback of the market, Google 
teams make their decisions about the modifications of their services and they are more confident of the consumer value they provide, because they know that Google is "never too far from what the markets want" (Google Inc., 2014, p. 3). Such a strategy Dale (2015) calls MVP, an abbreviation of Minimal Viable Product, which is "a machine for turning questions into answers". The idea behind it is in intentional down-stripping of the product to its core experience (see Lindemann, 2010, p. 109), otherwise, the excess of features would bring only confusion and difficulty in usage.

\subsection{From functionality to experience}

The most powerful brands do not rely on simple "core-product" characteristics that could be easily duplicated and blurred; it is actually the other way around. These influential brands count on the augmented and potential product to overcome physical competition and enter the consumer mind with a stronger message; they take advantage of any small chance to create an extremely distinctive and abstract image that appeals to audiences. In Keller's (1998, p. 94) explanation of brand knowledge, benefits are among the most influential associations that build these structures, and their importance lies in strengthening personal values and meanings. The role of experience may not be sufficiently apprehended independently of a product's physical conditions and functional premises. Its importance and complexity increases disproportionately according to the increase of the products' physical aspects and desirability.

In Levitt's (1980) concept of levels of product (see Figure 3) we can find traces of the modern assertion that the "consumer is the (real) product" and experience-emotive and/or cognitive - is the added value.

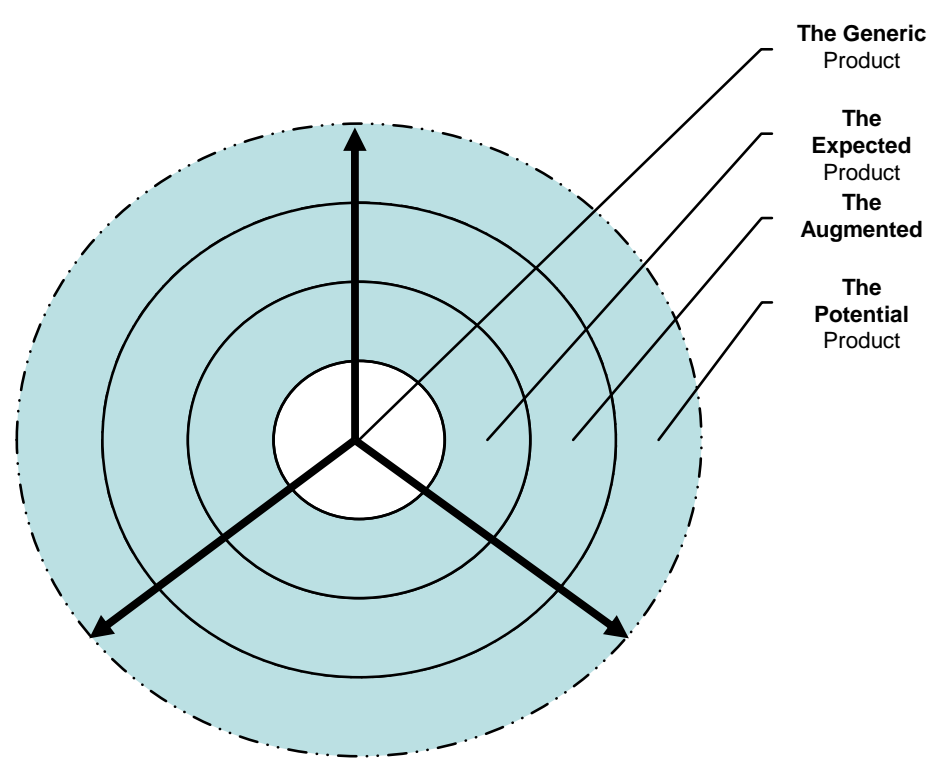

Figure 3. Levitt's concept of the layers of product (Levitt, 1980; adapted - D.T.).

The main merit of Levitt's thesis is the scrutiny of the widely spread assertion that there are commodities in the market which are not liable to differentiation. According to common opinion, those are goods which are only under the influence of the price and any correction in 
it sets the limits of the business. On the contrary, as Levitt (1980, p. 20) puts it:

There is no such thing as a commodity. All goods and services are differentiable. (...) In the marketplace, differentiation is everywhere. Everybody-producer, fabricator, seller, broker, agent, merchant - tries constantly to distinguish his or her offering from all others. This is true even of those who produce and deal in primary metals, grains, chemicals, plastics, and money.

Differentiation in terms of marketing and product development has to do with the manner of managing the communication process rather than with stressing on some special visible or presumable priorities of products. It is not unusual that product groups like coffee, salt, bananas, chickens, sausages and many more, which we are used to meet in the shops as branded and highly differentiated, were actually sold in the past as undifferentiated or minimally differentiated commodities (Levitt, 1980). Today commodities are known in the literature as "generic products" or put in semiotic parlance: they are products without any significance. It is true also that many companies that are currently among the biggest and strongest advertisers and consumer promotion makers do not neglect their active work with suppliers and distribution partners because aggressive trade policy is also a successful way to fight competitors. It goes to shows that the battle for consumers' attention and choice is spread out not only on a level of the media, but also on the level of space and shelf at the points-ofpurchase. Levitt takes the view that this proactive marketing approach demonstrates the lack of contradistinction between a "pull" and "push" strategy that increases brand power, both in consumers' minds and in the distribution channels' negotiations.

In order to support the assertion that every product could be differentiated, Levitt brings out several levels of apprehension of the notion according to the four levels displayed. For a start, Levitt presents the product as a combination of tangible (material) and intangible (nonmaterial) aspects and for this reason, in some cases, it is not possible for its full potential to be developed before consumer unless the latter is an expert in the area in question. Nevertheless, a product, even if it is a service or some insignificant goods at first sight, is not an object possessing an inherent value but a proposal and promise. The other name it has is "image", and it is the very carefully cultivated reputation of the producer whose overall message and meticulous packaging are as important as the physical content. Levitt illustrates this by means of the observation that customers never just buy the "generic" product like steel, or wheat, or subassemblies, or investment banking, or aspirin, or engineering consultancy, or industrial maintenance, or newsprint, or cosmetics, or even 99\% pure isopropyl alcohol. They buy something that transcends these designations — and what that "something" is helps determine from whom they will buy, what they will pay, and whether, in the view of the seller, they are "loyal" or "fickle". The product on the four levels is described by Levitt (1980) as following.

- Generic (core) product: a rudimentary, substantive "thing" that builds the basis of any given business, conditio sine qua non. The fact that such a kind of product is fundamental does not mean that all goods and services are equal even if they would be representatives of a particular market category. There are always some differences, although barely noticeable, between producers in quality of raw materials used, in the processes, methods or recipes in which the production goes or for which they offer various small additional services. All of them could be a reason for differentiation.

- Expected product: adds a package of minimal conditions and reasons that could initiate a purchase on the part of the consumer. These could be specific features of delivery, price formation, quality or payment towards the contracting part or the buying part expects advice from the suppler, support or new ideas for more effective usage of the product. 
- Augmented product: some extras and/or "unexpected" additional condition for the buyer come on stage in order to add value to the purchase. Very often, however, consumers just do not have any need for such complements or even in times of intensive price competition, namely price reduction becomes an instrument for creating complementary benefits to the purchase.

- Potential product: embraces everything that could be used and done for consumers' attraction. In this case, only the restrictions of the budget as well as of the managers' imagination would define how far the opportunities could reach. On this level, regular and multidisciplinary studies on consumers' needs, behavior patterns and attitudes would be useful for any product modifications and improvements. The potential here lies in that the manager is able to present a product in more favorable light for the consumer introducing redesign, new usages or attributes augmentation. Arguably, this is the level that is most interesting from a semiotic standpoint.

If we take a restaurant as a model of service, the layers are easily visible for an average consumer. Food is the core product in which taste always matters. Most of the restaurants, however, serve similar dishes, and this blurs their advantages. The features of the expected product embrace location, tables' disposition, type of background music, menu the scope of choice found in the menu, etc. (Jacobsen, 2008, p. 26; Oliver, 1999, p. 48). The augmented product includes possible customization of the service, i.e. a special menu, serving quality above expectations or additional decoration. From this point on anything could be set into operation - some extra dishes, individual music request, and particular paying opportunities. In much the same manner Schultz made the coffee culture revolution by introducing his vision about the message of the Starbucks' coffee-houses as authentic coffee-maker and pleasant place to have a good cup of coffee. This chain serves to mass-market the Italian espresso bar experience using a shift towards cultural sophistication, decoded from the artisanal and elite coffee culture and applied to urban middle-class, which had discarded the orthodoxy of using Colombian brands and demanded lifestyle products (Holt and Cameron, 2010, pp. 84-85; Thompson and Arsel, 2004). This step could not be possible without the favorable market context (e.g. avoiding "fast food" behavior) and most importantly, without certain sensorial stimulation (Lindstrom, 2005, p. $157 \mathrm{ff}$.).

Finally, Levitt (1980) concludes that a product is not a constant quality that can be described easily with textbook terminology. The definition of a product depends on economic conditions, stages of the consumer culture, business strategies, market expectations as well as number and strengths of the competitors. These are powerful factors of perception defined by their respective positioning statements, promotional activities, quality improvement and innovations, etc., since there is almost no product that "stands alone" in the market. Therefore, the notion of "product" varies ceaselessly according to the context in which given product is scrutinized. It is possible that a commodity or service perceived as "augmented" by one consumer is actually "expected" by others. Moreover, due to questionable market situations, e.g. embarrassed supplies, the "expected" product could readily turn into a "generic" product. Levitt notes that to the buyer "a product is a complex cluster of value satisfactions. The generic thing is not itself the product... (...) Customers attach value to a product in proportion to its perceived ability to help solve their problems or meet their needs. All else is derivative" (1980, p. 20, author's emphasis).

The brand as a managerial instrument in building differentiation and added value could come into use on any other product level beyond the "generic" one in regard to strategic corporate objectives and market particularities. In reality, the brand management for today is a "core product", it is just a notion for the sake of convenience, a production hypothesis, since 
in principle goods and services are launched by well-prepared strategic marketing and communication plans. Likewise, in the industrial sector, a product could almost never be seen in its pure form (the product as it is). The image of the producer or supplier is a source of secondary brand associations, as it has its influence on the buyer's final decision (Keller, 1998, p. 269). Of course, the level of "potential" product is the sphere in which the symbolic world of a brand (some name it "psychological" or "non-material") does not have any limits and companies use all possible communication channels and impact methods to maintain and develop it in prospects' and current clients' minds. The goal of the approach is twofold - to make the messages of competition irrelevant (e.g. hard to be copied) and to sustain the relationships with consumers (especially the loyal ones) (Aaker, 1996, 2011).

Pine and Gilmore (1999) add a useful tool for evaluating the path of a product from commodity to transformation. Their pyramid model displays commodities on the lowest level where they are produced in terms of culture-as-production, but still "noises in the air" keep their value in the zone of insignificance (needed but not important and hard to distinguish). Gradually, products advance upwards and increase their value in consumers' perceptions and attitudes. As depicted (Figure 4), experience correlates with knowledge, which presupposes, on its part, active attention and participation on behalf of consumers and intensive information transition via various channels. What deserves special attention, however, is the top of the model because it is a demonstration of the assertion made above. It turns out that "experience" is a necessary stage that leads to "transformation", but not the highest level in itself. The most overt transformational processes are, first, the initiation of a product to a virtual or real consumer group and, second, the change of the world by means of a particular product. That is why only a few brands, mostly suitable to modern (mobile, dynamic) lifestyles, have succeeded to reach the highest level and to involve their consumers to full commitment (Lego, Apple, Nike, Harley-Davidson). "Wisdom" regarding products stands for a set of knowledge, skills and (past) experience. It leads to a transformation of the consumer, since wisdom is a shared value between him or her and the manufacturer/provider.

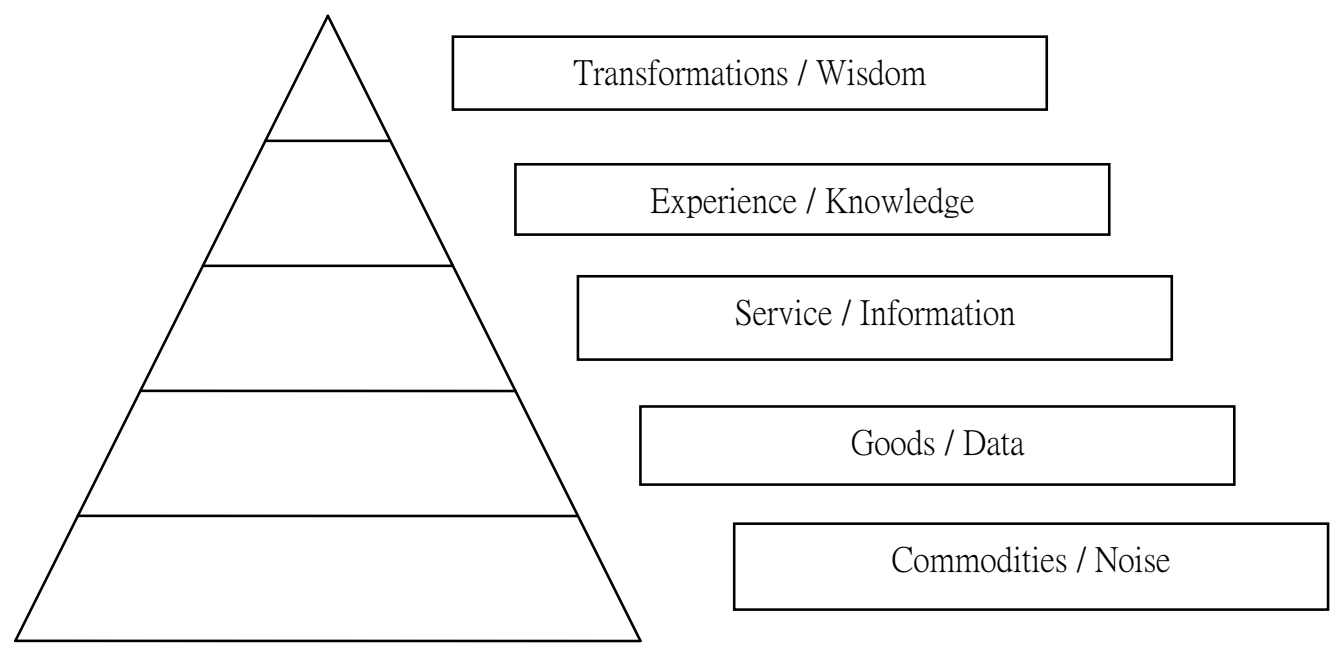

Figure 4. A pyramid model of the progressions of Economic Value and Valuable intelligence by Pine and Gilmore (1999, p. 188; adapted - D.T.)

By experiencing the use of products and services' attributes, a consumer acquires information about what a given brand could do for her or him and forms "reasons-to-buy". The distinction here is what criteria is motivated and connected to the purchase benefits - 
functional, symbolic or experiential (Keller, 1998, p. 99), that can be explained as follows.

- Functional benefits usually correspond with product-related attributes of a given brand. They are based on the intrinsic advantages provided by products. Basically, these benefits are linked to motivations from the bottom levels of Maslow's hierarchy of needs - physiological and safety as including natural and emerging problem avoidance or removal (Maslow, 1943). Even globally recognized shampoo brands have to satisfy needs of eliminating dandruff, making the hair healthy and giving it moisture by manifestly fixing such kind of physical problems (Keller, 1998, p. 99), otherwise they would be erased from the market map regardless of the volume of advertising and richness of imagery.

- Symbolic benefits are a style of imagery related to external advantages as a result of product use. These correspond with non-product-related attributes of given goods or services and are predominantly connected with the idea of the product's user. Advertising is the usual, although not the only, channel for providing this imagery (Keller, 1998, p. 99). By doing so, companies try to make the consumer's choice easier, demonstrating how he or she could look in others' eyes as an effect of how the brand performs. Symbolic benefits' roots in the satisfaction of social needs (approval), self-confidence building, and (which is even much more important) personal expression (Keller, 1998, Aaker and Joachimsthaler, 2000). Continuing with the shampoo example, Keller specifies (1998, p. 99) that the so-called "badge products" make the audience believe that they bear personal information to others. Thus a particular brand assures its consumers that "beautiful people", "selfconfident" and "enjoying good live" are using exactly its products.

- Experience-based benefits are linked to the feeling of product or service use in the moment of consumption, and they could embrace both product-related and nonproduct-related attributes (e.g. price ${ }^{4}$, imagery, distribution). Their relation with $u$ ser imagery - who is the consumer, as well as usage imagery - where, when and how the product should be used - is direct (Keller, 1998, pp. 93-95). These benefits are meant to satisfy experiential needs such a sensory pleasure (sight, taste, sound, smell or feel), variety, and cognitive stimulation (Keller, 1998, p. 100) and shampoo is expected to provide feelings of cleanliness, freshness and strong aroma. Even though the author avoids the rational arguments in his benefits as well as emotions taxonomy, they take their place in certain degrees in each of the three mentioned "benefits' packages" offered by brands. Briefly said, we should seek for emotionally driven consumer behavior almost everywhere and managers have to cultivate the energy of their consumers' emotions in long-lasting trust and preference which means loyalty and business stability.

\footnotetext{
${ }^{4}$ Price is probably the most distinctive feature in market systems and usually it is not a matter of production but of consumption. Thereby its place is exactly in the group of non-product-related attributes and its role in experience-providing is not less important than that of the other elements in the product set. However, it is an interesting fact that Friedrich von Hayek (1945) expressed his thoughts on price in semiotic terms, rather than by using the casual economic style of writing. He named it "a type of symbol" thanks to which in very delightful manner individuals, interested in some goods in the market, receive only the most essential part of the information which points out the changes and attitudes occurring in the society spectrum. The price mechanism is a cultural artifact, build upon institutionalized practice and habits, that the members of society learn to use in their entire lives, although very often they are not able to explain readily what is it and how it works (Hayek, 1945, pp. 527-528; see also Kopytoff, 1986).
} 


\section{Multimodality and its application in experiential branding}

Multimodality (see Kress, 2003 for an introduction) has finally found its merited place in the realm of brand semiotics, and is noteworthy as an appropriate analytical method with roots in social semiotics (Culache, 2014; Rossolatos, 2015). Multimodality helps in brand experience development by stimulating one or more forms of interaction with consumers according to the given product category. Moreover, it provides a nuanced understanding of how cultural agents use and utilize cultural resources in order to generate and share meaning out of everyday activities (Rossolatos, 2015, p. 6), which has strong connection with brands' behavior insofar as they act predominantly on a daily routine but aim to keep consumers committed and inspired (Fournier, 1998).

Table 2. Dimensions of the multimodal ensemble suggested. Put in communication terms, the table combines code - channel - medium - sensory stimulation (Page, 2010, p. 7).

\begin{tabular}{|l|l|l|l|}
$\begin{array}{l}\text { Textual } \\
\text { resources }\end{array}$ & $\begin{array}{l}\text { Platform } \\
\text { of delivery }\end{array}$ & $\begin{array}{l}\text { Physical } \\
\text { environment }\end{array}$ & $\begin{array}{l}\text { Sensory } \\
\text { modalities }\end{array}$ \\
\hline Words & Digital screen & Private (domestic) & Sight \\
\hline Image & Printed page & Public & Hearing \\
\hline Sound & Cinema/TV screen & $\begin{array}{l}\text { Inside/Outside } \\
\text { rooms or buildings }\end{array}$ & Touch \\
\hline Movement & Face-to-face & Light/Dark & Smell \\
\hline Olfactory resources & Telephone & Objects/Space & Taste \\
\hline
\end{tabular}

In short, the social-semiotic notion of multimodality deals with modes that parties usually use in their communication: visual, verbal, tactile, aural and olfactory. In reality these modes collaborate and jointly shape the complete message (Kress, 2003, p. 36; 2010, pp. 3033). Kress defines multimodality as socially built semiotic resources for meaning-making (2010, p. 79), which describes the multi-channel performance even in a simple act of everyday conversation. In branding practices, integrated marketing communications (also known as "marketing 360") and especially retail management (Oswald, 2015) have been adopted exactly with the same goal - the avoidance of mono-dimensionality of the brand message and the increase of the latter's effectiveness and consumer participation. For instance, managers very often consider the concept of "Integrated Marketing Communications" quite narrowly by putting the stress on visual and verbal modes. Rather, "multi-semiotic mechanisms, implying the use of multiple semiotic resources, are strongly connected to multimodality, that uses various modes to convey a message", and "multimodality can offer brands the opportunity to create and convey multi-sensory messages, capable of having a greater impact on consumers" (Culache, 2014). Brand specialists are able to translate the message from one mode to another by choosing from the range of available modes (words [radio] to image [billboards]) and/or according to the culture they operate in, in order to sophisticate and improve the brand message (see Table 2). That is what Kress (2010, p. 169) names "ratification" or a process of fine tuning or re-articulation, whereby meaning is translated from less to more implicit, according to the context.

Clearly, multimodality has a strong connection with brand sensorial management, both with respect to intentionally branded market environment, and products (Kozinets, 2008; Trendafilov, 2014). Lindstrom (2005) calls our attention to the fact that for long time 
marketing has been dominated by 2-D concept for brand perception (via eyes and ears, represented only by the TV screen and print ads), since marketers have been underestimating the influence of the store environment and real purchasing situations. In fact, about $80 \%$ of parents' purchases are influenced by their children, whose senses are at least two times stronger (Underhill 2009) and multi-sensory messages directly influence the perceived quality of the product, which in turn affects the value/price of the brand as well. Relatively few people deliberately think of taste or smell when they are asked about cars However, daily routines reveal that many individuals eat and drink coffee in their cars, and subsequent sensorial associations could be positive or negative. Moreover, the human senses work in combination and the higher the number of sensory memories activated the stronger the bonding between brand and consumer (Solomon et al., 2006, Lindstrom, 2005). Consumers "assess" brands mostly through their senses and more deeply through a combination of the senses. A gradation according to the "Attention - Information - Feeling - Bonding" process is available as well (Lindstrom, 2005; Solomon et al., 2006). While sensation is an "immediate response of our sensory receptors to such basic stimuli as light, color, sound, smell, material structure", perception is "the process by which the stimuli are selected, organized and interpreted". According to this theory, in this way we assign meaning to "raw" data from the outer world (Solomon et al., 2006, p. 36). In the points-of-purchase, as detailed in Section 2 the whole environment has its influence in the particular zone, brands' names, package design, its elements and colors as well as their harmony. All of this is preceded by the consumer experience with the product and conditioned by given cultural attitude towards the various types of goods. This then can help to illustrate the success of several brands by their deep understanding of both the universal qualities of human behavior and the cultural context of the local markets in which they operate (Gains, 2015).

Evidence of significant change that has appeared in the market because of the Internet is provided by the problems which traditional retailers have been experiencing since the beginning of the century. McArdle (2012) describes the decreasing sales of the leading American "category killer" until recently, Best Buy, facing the competition of Amazon and similar online retailers. As a result of the intensive online searching (for price comparison, for promotions and bargains and so on), which is a kind of newly emerged experience for the mass market, two new phenomena have been observed. The first one is "showrooming", which extends and even replaces "window shopping", which arose in the past when "brickand-mortar" used to have a dominant position. According to the research data, up to $46 \%$ of the people in the U.S. go into stores to see the goods in their real dimensions before making their purchase online (McArdle, 2012).

The second one, which is in direct connection with the previous one, is that many important vendors actually count more on online trade and use offline stores predominantly as windows to display their brands without making any investments in retail (McArdle, 2012, p. 39). In this situation, Best Buy and many others conform to the market realities and try to save their businesses by implementation of the opposite strategy, followed by the high-end retailers which then provide "a browsing experience and break of the everyday" (McArdle, 2012, p. 36). In their efforts to stop in-store "tourism", middle and low-end retail chains started to cut their merchandise offers and improve their services and layouts, instead of trying to maintain wide range of products on their shelves as previously.

Nowadays, storytelling, as both a form of communication and specific experiential tool, takes place via various channels. On account of its objectives, the role of brand managers as strategic surveyor of consistence and supplying the story is increasing. However, as practice indicates, brands that best tell their stories control the context: "The influence of Apple store goes beyond the consumer experience by making a statement that affects the image. It is not 
necessary to have a chain to capture substantial sales" (Aaker, 2011, p. 313). To global brands like Nike, Sony, Apple or Tommy Hilfiger the physical in-store space exceeds the traditional function of sales space and live billboard simultaneously in order to serve as an interactive and compelling experience arena. Experience is not organized towards easy and pleasant buying process for consumers, but rather to "practicing" a particular brand in completely onbrand way (Kozinets, 2008; see Oswald, 2015, p. 97 ff.; Lindemann, 2010, p. 116).

Nespresso, for instance, has demonstrated significant improvement in its brand experience, which is crucial for the coffee business in principle, by constant modification and improvement of the modes (Piercy and Lane, 2009, p. 81). It started with mail-order distribution of its capsules for espresso machines for a narrow audience. Then the brand launched its own special designed coffee machines and in this case, shapes and colors play dominant roles, providing both aesthetical experience and exclusivity. The next goal was HoReCa channel (i.e. Hotel and Catering industry) that should provide the first-hand consumer experience to wider audience through selected retailers. The last step for Nespresso was to open boutiques at the prestigious locations in trendsetting cities like London, New York and Turin. The interior of each shop is decorated in black wood and plush, the capsules are ordered in colors, and the personnel follow a strict dress code, alluding to a high-end fashion retail or 5-star hotel lounge. The main idea behind Nespresso's expansion (Futurebrand, 1999) is not to emphasize the product's supremacy, but also not to allow retailers (or any third party) to take control over the brand experience. By creating and selling machines, accessories and specific ambience the brand offers superior service which is a unique halo around the coffee (Oswald, 2015, p. 53 ff.). Even though the taste of Nespresso coffee is excellent and the consumer has a significant range to choose from, the brand would not be able to reach the high level of equity (e.g. its own distinguished meaning) without the "experiential" devices it has provided. The consumer eventually receives one overall integrated meaning that varies from functional benefits (taste, aroma, choice, convenience) through symbolic complements (packaging, branded accessories, buying from company's own retail) to a social aspect (being part of Nespresso culture). This process is a direct evidence of how, by use of various and brand-relevant channels and code systems, a brand could create and maintain its image, which is a hub consisting of unique, favorite and strong associations (Keller, 2013, p. 78). The intensity and multimodal richness of the communication make the difference between traditional advertisement and experience as a branded message. Put in this light, experience seems to be the strongest mechanism in providing brands with the Holy Grail of brand management: "top of the mind" position, fast recall in a buying situation, and behavioral loyalty.

Although it was not associated with instant coffee or cosmopolitan fancy image like Nespresso, Lavazza took almost the same steps on account of the increase of consumer experience. The brand became synonymous with high-quality coffee blends for home and retail consumption with strong Italian roots, but in order to improve its offer by means of ready-to-drink products and to enter the experience stage of the market, Lavazza opened its own special coffee-houses and locked out the value of its "hospitality" in its famous slogan "The real Italian espresso experience" (Bankov, 2011, p. 259). Being a world famous brand because of the powerful slogan and trade channels is not enough. Therefore, Lavazza mixed verbally and imaginatively articulation of experience with sensorial stimulations. The difference with Nespresso is the limited number of outlets and the strong accent on the Italian coffee tradition in general. Thus, Lavazza "monopolizes" Italian-ness as a secondary brand association and positions itself as traditional and authentic, instead of cosmopolitan and luxury. 


\section{Conclusions}

This article started with the emphasis on the leading role of experience in the new economy and an increasing involvement of the consumer in its production and realization. This phenomenon has become generally known as "prosumeration". The role of brands in mediating the process is significant as they are powerful tools of communication with consumers. However, we have argued that the human senses, when used in the right context, are the channels that provide relevant brand experience, especially when traditional advertising hardly implements its tasks. The meaning that consumers attach to the impressions, signals and stimuli they receive from the outside world is not original; rather it is determined by associations coming from previous experiences as well as shaped into a broader social formation. Thus, multimodality allows brand management to rearrange the product and brand perceptions that form the multidimensional collaboration with contemporary consumers looking for "authenticity" and an active position regarding the production-consumption process.

Brand semiotics mediates between call for action and reaction (in a marketing perspective) and between meaning generation and meaning circulation (in a socio-cultural perspective). This is a dynamic and multilevel relationship between addresser and addressee. On the one hand, there is the artificially produced entity called "the brand", and on the other: the biologically and culturally shaped economic subject, generally known as "the consumer". Semiotics fits brand building and development, not only because it stresses the important role of the consumer in market exchange, but also because it considers the social-cultural context and the relevant details in the communication mechanism.

\section{Acknowledgments}

The author would like to thank the editorial team of Public Journal of Semiotics for the opportunity to publish this article as well as the anonymous reviewers for their suggestions that were very important for the article's improvement.

\section{References}

Aaker, D. A. (1996). Building strong brands. New York, NY: The Free Press.

Aaker, D. A. \& Joachimsthaler, E. (2000). Brand leadership. New York, NY: The Free Press.

Aaker, D. A. (2011). Brand relevance. Making competitors irrelevant. San Francisco, CA: John Wiley \& Sons, Inc.

Appadurai, A. (1986). Introduction: Commodities and the politics of value. In Appadurai, A. (Ed.), The social life of things: commodities in cultural perspective (pp. 3-63). Cambridge, UK: Cambridge University Press.

Baldwin, C. Y. \& Clark, K. B. (2000). Managing in an age of modularity. In Pine, J. \& Gilmore, J. (Eds.). Markets of one: creating consumer-unique value through mass customization (pp. 35-52), Boston, MA: Harvard Business School Press.

Bankov, K. (2011). Technology, the imaginary, and the transfer of experience: between the market and social networks. Lexia. Revista di Semiotica, 7/8. "Imaginario". 255-278.

Barthes, R. (1972). Mythologies. New York, NY: Farrar, Straus and Groix.

Batey, M. (2008). Brand meaning. New York, NY and London, UK: Routledge.

Brakus, J. J. (2008). Embodied cognition, affordances, and mind modularity: using cognitive 
science to present a theory of consumer experience. In Schmitt, B. H. \& Rogers, D. L. (Eds.). Handbook on brand and experience management (pp. 144-162), Cheltenham, UK \& Northamption, MA: Edward Elgar.

Brakus, J. J., Schmitt, B. \& Zarantonello, L. (2009). Brand experience: What is it? How is it measured? Does it affect loyalty?. Journal of Marketing, 73, 52-68.

Bullmore, J. (2001). Posh spice \& Persil. In The British brands group Library, Retrieved from: http://www.britishbrandsgroup.org.uk/search?text=Bullmore \&x $=0 \& \mathrm{y}=0$.

Codeluppi, V. (2001). Il potere della marca. Disney, McDonald's, Nike, e le altre. Torino, It: Bollati Boringhieri.

Copley, P. (2004). Marketing communications management: concepts and theories, cases and practices. Oxford, MA: Elsevier Butterworth-Heinemann.

Culache, O. (2016). Shifting from channels and codes to modes: a reconceptualization of brand communication to mulitimodality. In Bankov, K. (Ed.). The proceedings from the IASS/AIS $12^{\text {th }}$ world congress of semiotics - Between tradition and innovation. Sofia. 1622 September 2014, in the press.

Dale, L. (2015). The experience makes the product, not the features, Retrieved from http://uxmag.com/articles/the-experience-makes-the-product-not-the-features.

Eco, U. (1976). The theory of semiotics. Bloomington, IN: Indiana University Press.

Floch, J.-M. (2001). Semiotics, marketing and communication. Houndmills, UK and New York, NY: Palgrave Publishers Ltd.

Fournier, S. M. (1998). Consumers and their brands. Developing relationship theory in consumer research. The Journal of Consumer Research, 24(4), 343-373.

Fournier, S. M., Sele, K. \& Schögel, M. (2005). The paradox of brand community "management". Marketing Review St. Gallen-Thexis, 3, 16-20.

Fournier, S. M. \& Lee, L. (2009). Getting brand communities right. Harvard Business Review, 24(4), 105-111.

Futurebrand (1999). Nespresso case study. The future of coffee experience, Retrieved from http://www.futurebrand.com/images/uploads/clients/casestudies/Nespresso-CaseStudyp.pdf.

Gains, N. (2015). Human decision-making and the semiotics of sensory signals, Retrieved from https://rwconnect.esomar.org/human-decision-making-and-the-semiotics-of-sensorysignals/.

Google Inc. (2014). Creating a culture of innovation. A Google for work perspective paper, Retrieved from http://lp.google-mkto.com/rs/google/images/WP-Creating-CultureInnovation.pdf?mkt tok=3RkMMJWWfF9wsRolv67Jc\%2B\%2FhmjTEU5z16e0vWqC0 gpx41El3fuXBP2XqjvpVQcZnNLjORw8FHZNpywVWM8TILtQYt8FtKAzgAG0\%3D.

Hayek, F. A. (1945). The use of knowledge in society. The American Economic Review, 35(4), 519-530.

Hofstede, G. H., Hofstede, G. J. \& Minkov, M. (2010 [2005]). Cultures and organizations. Software of the mind: international cooperation and its importance for survival. Revised and expanded. 3rd ed. New York, NY \& Chicago, Il: The McGraw-Hill Companies, Inc.

Holbrook, M. B. \& Hirschman, E. C. (1982). The experiential aspects of consumption: consumer fantasies, feelings and fun. Journal of Consumer Research, 9(2), 132-140.

Holt, D. \& Cameron, D. (2010). Cultural strategy. Using innovative ideologies to build breakthrough brands. Oxford, UK \& New York, NY: Oxford University Press.

Jacobsen, J. K. (2008). The food and eating experience. In Sundbo, J. \& Darmer, P. (Eds.). Creating Experiences in the Experience Economy (pp. 13-32), Cheltenham, UK \& Northampton, MA: Edward Elgar.

Joseph, J. (2010). The experience effect. Engage your consumers with a consistent and 
memorable brand experience. New York, NY, Brussels, Bel. \& Shanghai, China: American Management Association.

Kahneman, D. (2013). Thinking, fast and slow. New York, NY: Farrar, Straus and Giroux.

Kapferer, J.-N. (2012). The new strategic brand management. Advanced insights and strategic thinking. $5^{\text {th }}$ ed. London, UK \& Philadelphia, PN: Kogan Page Ltd.

Keller, K. L. (1998). Strategic brand management. Building, measuring, and managing brand equity. New Jersey, NJ: Prentice Hall, Inc.

Keller, K. L., Apéria, T. \& Georgson, M. (2012). Strategic brand management. An European perspective. $2^{\text {nd }}$ ed. Harlow, UK: Pearson Education Ltd.

Keller, K. L. (2013). Strategic brand management. Building, measuring, and managing brand equity. $4^{\text {th }}$ Global ed., Harlow, UK \& Boston, MA: Pearson Education Ltd.

Klein, N. (2000). No logo. London, UK: Flamingo.

Kopytoff, I. (1986). The cultural biography of things: commoditization as process. In Appadurai, A. (Ed.) The social life of things: commodities in cultural perspective (pp. 6491), Cambridge, UK: Cambridge University Press.

Kotler, P. (1986). Prosumers: a new type of consumer. Futurist (Sep.-Oct.), 24-28.

Kotler, P., Kartajaya, H. \& Setiawan, I. (2010). Marketing 3.0. From products to consumers to the human spirit. Haboken, NJ: John Wiley \& Sons.

Kotler, P. \& Keller, K. L. (2012). Marketing management. 14th Global ed. Harlow, UK: Pearson Education Ltd.

Kozinets, R. V. (2008). Brands in space: new thinking about experiential retail. In Lowrey, T. M (Ed.). Brick \& mortar. Shopping in the $21^{\text {st }}$ century (pp. 3-15), New York, NY: Lawrence Erlbaum Associates.

Kress, G. (2003). Literacy in the new media age. London, UK \& New York, NY: Routledge.

Kress, G. (2010). Multimodality. A semiotic approach to contemporary communication. London, UK \& New York, NY: Routledge.

Levitt. T. (1980). Marketing success through differentiation - of anything, Retrieved from https://hbr.org/1980/01/marketing-success-through-differentiation-of-anything/ar/1.

Lindemann, J. (2010). The economy of brands. London, UK \& New York, NY: Palgrave Macmillan.

Lindstrom, M. (2005). Brand sense: build powerful brands through touch, taste, smell, sight, and sound. New York, NY: Free Press.

Marrone, G. (2007). Il discorso di marca. Modelli semiotici per il branding. Roma-Bari, IT: Laterza \& Figli.

Maslow, A. (1943). A theory of human motivation. Psychological Review, 50 (4), 370-396.

McArdle, M. (2012, December 10). Shopping becomes a mini-vacation. Newsweek, 34-39.

McLuhan, M. \& Nevitt, B. (1972). Take today. The executive as dropout. New York, NY: Harcourt Brace Jovanovich.

Mick, D. G., Burroughs, J. E., Hetzel, P. \& Brannen, M. Y. (2004). Pursuing the meaning of meaning in the commercial world: an international review of marketing and consumer research founded on semiotics, Semiotica, 152, 1/4, 1 - 74.

Lotman, Y. (1992). Култура и информация [Culture and information], Sofia, BG: Nauka i Izkustvo.

Oliver, R. L. (1999). Value as excellence in the consumption experience. In Holbrook, M. (Ed.). Consumer value. A framework for analysis and research (pp. 43-62), London, UK \& New York, NY: Routledge.

Oswald, L. R. (2012). Marketing semiotics. Signs, strategies, and brand value. London, UK \& New York, NY: Oxford University Press.

Oswald, L. R. (2015). Creating value: the theory and practice of marketing semiotics 
research. Oxford, UK \& New York, NY: Oxford University Press.

Page, R. (2010). Introduction. In Page, R. (Ed.). New perspectives on narrative and multimodality (pp. 1-13), New York, NY \& London, UK: Routledge.

Piercy, N. F. (2009). Market-led strategic change. A guide to transforming the process of going to market. $4^{\text {th }}$ ed., Oxford, UK: Elsevier Ltd.

Piercy, N. F. \& Lane, N. (2009). Strategic consumer management. Strategizing the sales organization. Oxford, UK: Oxford University Press.

Pine, J. \& Gilmore, J. (1999). The experience economy. Work is theatre \& every business is a stage. Boston, MA: Harvard Business School Press.

Pine, J., Victor, B. \& Boynton, A. C. (2000). Making mass customization work. In Pine, J. and Gilmore, J. (Eds.). Markets of one: creating consumer-unique value through mass customization (pp. 149-166), Boston, MA: Harvard Business School Press.

Prahalad, C. K. \& Krishnan, M. S. (2008). The new age of innovation. Driving cocreated value through global networks. New York, NY \& London, UK: McGraw-Hill.

Rifkin, J. (2000). The age of access: The new culture of hypercapitalism, where all of life is a paid-for experience. New York, NY: Putnam Publishing Group.

Rossolatos, G. (2015). Taking the "multimodal turn" in interpreting consumption experience. Consumption Markets \& Culture, 18(5), 427-446.

Schouten, J. W. \& McAlexander, J. H. (2005). Subcultures of consumption: an ethnography of the new bikers. Journal of Consumer Research, 22, 43-61.

Solomon, M., Bamossy, G., Askegaard, S. \& Hogg, M. K. (2006). Consumer behavior. An European perspective. $3^{\text {rd }}$ ed. Harlow, UK \& New Jersey, NJ: Prentice Hall, Inc.

Strategic Business Insight (2015). Experiencers. Retrieved from http://www.strategicbusinessinsights.com/vals/ustypes/experiencers.shtml.

Toffler, A. (1981). The third wave. New York, NY: Bantam Book and William Morrow Co.

Thompson, C. J. \& Arsel, Z. (2004). The Starbucks brandscape and consumers' (anticorporate) experience of glocalization. Journal of Consumer Research, 31(3), 631642.

Trendafilov, D. (2014). Brand sense or sensitive to brand? [ESOMAR RWConnect], Retrieved from https://rwconnect.esomar.org/brand-sense-or-sensitive-to-brand/.

Trompenaars, C. \& Hampden-Turner, F. (1997 [1993]). Riding the waves of culture: understanding cultural diversity in business. London, UK: Nicholas Brealey Publishing.

Underhill, P. (2009[1999]). Why we buy? The science of shopping. New York, NY: Simon and Schuster Paperbacks.

Vincent, L. (2002). Legendary brands. Unleash the power of storytelling to create a winning marketing strategy. Chicago, Il: Dearborn Trade Publishing.

Williamson, J. (2000[1978]). Decoding advertisements: ideology and meaning in Advertising. London, UK: Marion Boyars.

Author address

dtrendafilov@nbu.bg

About the author

Dimitar Trendafilov is MBA and PhD in semiotics. He is regular lecturer in Marketing, Branding and Research at New Bulgarian University - Sofia and consultant in commercial communications area. 